\title{
Orographic Factors as a Predictor of the Spread of the Siberian Silk Moth Outbreak in the Mountainous Southern Taiga Forests of Siberia
}

\author{
Svetlana M. Sultson ${ }^{1}$, Andrey A. Goroshko ${ }^{1}$, Sergey V. Verkhovets ${ }^{1}$, Pavel V. Mikhaylov ${ }^{1, *}$, Valery A. Ivanov ${ }^{1}$, \\ Denis A. Demidko ${ }^{1,2}$ and Sergey S. Kulakov ${ }^{1,2}$
}

1 Scientific Laboratory of Forest Health, Reshetnev Siberian State University of Science and Technology, 31, Krasnoyarskii Rabochii Prospekt, 660037 Krasnoyarsk, Russia; sultson2011@yandex.ru (S.M.S.); goroskoaa@sibsau.ru (A.A.G.); verkhovets_sv@sibsau.ru (S.V.V.); ivanovv53@yandex.ru (V.A.I.); sawer-beetle@yandex.ru (D.A.D.); kulakov_ss@sibsau.ru (S.S.K.)

2 Sukachev Institute of Forest, Siberian Branch, Russian Academy of Science, 50, bil. 28, Akademgorodok, 660036 Krasnoyarsk, Russia

* Correspondence: mihaylovpv@sibsau.ru

check for updates

Citation: Sultson, S.M.; Goroshko, A.A.; Verkhovets, S.V.; Mikhaylov, P.V.; Ivanov, V.A.; Demidko, D.A.; Kulakov, S.S. Orographic Factors as a Predictor of the Spread of the Siberian Silk Moth Outbreak in the Mountainous Southern Taiga Forests of Siberia. Land 2021, 10, 115. https://doi.org/10.3390/land10020115

Academic Editor: Eusebio Cano Carmona

Received: 22 December 2020

Accepted: 22 January 2021

Published: 26 January 2021

Publisher's Note: MDPI stays neutra with regard to jurisdictional claims in published maps and institutional affiliations.

Copyright: (c) 2021 by the authors Licensee MDPI, Basel, Switzerland. This article is an open access article distributed under the terms and conditions of the Creative Commons Attribution (CC BY) license (https:// creativecommons.org/licenses/by/ $4.0 /)$.

\begin{abstract}
This research is dedicated to solving an urgent problem associated with the large-scale destruction of taiga forests by Siberian silk moth (Dendrolimus sibiricus) outbreaks. The dynamics of the damage to dark coniferous forest stands induced by the Siberian silk moth outbreaks in mid-altitude mountains were studied. A hypothesis was formulated based on the fundamental influence of the orography on the phytophage's dispersal within the landscape, along with the climate, which acts as a secondary predictor-a catalyst for outbreaks. The study was carried out using Landsat -8 satellite imagery time-series (from 2018 to 2020). The data were verified using a field forest pathological survey of the territory. An assessment of the defoliated forest area and damage association with the landscape was carried out using an Advanced Spaceborne Thermal Emission and Reflection Radiometer (ASTER) digital elevation model. The assessment was aimed to detail the forecast parameters for an outbreak development in mid-altitude mountains using the orographic features-altitude, terrain slope, and slope aspect. Early warnings of phytophagous insect outbreaks in mountain southern taiga should be focused on the permanent monitoring of dark coniferous stands of the mossy group of forest types, covering altitude levels from 400 to $600 \mathrm{~m}$, located on gentle terrains and slopes of up to 15 degrees. The greatest vulnerability to phytophage impacts was characterized as areas located at altitudes from 400 to $600 \mathrm{~m}$. The upper limit of D. sibiricus distribution was $900 \mathrm{~m}$ above sea level. The results obtained provide comprehensive information on the Siberian silk moth potential reserves within the study area with the possibility of extrapolation to similar territories. The data will make it possible to model pest outbreaks based on orography and improve the forest pathological monitoring methods at the regional level.
\end{abstract}

Keywords: forest pathology; monitoring; digital elevation model; Dendrolimus sibiricus; forest damage; spatiotemporal dynamics; Siberian stone pine (Pinus sibirica Du Tour); Siberian fir (Abies sibirica L.); forest type

\section{Introduction}

The Siberian silk moth (Dendrolimus sibiricus) is an integral part of taiga forest ecosystems [1-4]. This species is one of the most dangerous phytophages in its range. The $D$. sibiricus population area covers a vast territory of coniferous forests. It is the primary pest of forests of the Urals, Siberia, the Russian Far East, as well as Mongolia, China, and Korea [3-7]. This phytophage's permanent habitats within a natural complex are not accidental and are often confined to host-tree areas combined with specific temperature and humidity conditions [8-11]. The phytophage outbreaks are cyclical and periodically 
repeated when favorable conditions are created due to long dry, hot periods during the previous 2-3 years $[3,12]$.

Massive larval feeding on tree crowns leads to forest death, causing enormous economic and environmental damage. In this regard, special attention is paid to the monitoring and control of this phytophage. Long-term forest pathological surveys showed that nine D. sibiricus large-scale outbreaks occurred in the Krasnoyarsk Krai forests from 1878 to 1998, affecting over 8 million hectares. A widespread (panzonal) outbreak was recorded from 1989 to 1997, which destroyed 1 million hectares of dark coniferous taiga. In 20142018, dead plantation territory in the central regions of the Krasnoyarsk Krai covered over 800 thousand hectares.

At the moment, this territory, with a stock of standing deadwood over 200 million cubic meters, is at risk of catastrophic fires and secondary pest outbreaks. The latest Siberian silk moth outbreak in the study area occurred in 2019-2020 [13]. This outbreak occurred in the mountainous southern taiga forests of the Krasnoyarsk Krai and destroyed approximately 20 thousand hectares of cedar and fir forest stands.

Previously repeated outbreaks in this region are mentioned in the studies of P.P. Okunev, Yu.P. Kondakov, and V.I. Haruk [4,10,13-15]. The works are devoted to the geographical distribution and chronology of D. sibiricus outbreaks. The authors noted that outbreaks predominantly occur in fir-dominant forests. As a result of studying the chronology of outbreaks, V.I. Kharuk revealed an expansion of the geoclimatic zone of the Siberian silk moth distribution in Siberia [13]. Thus, the Siberian silk moth issue continues to be relevant. Global warming creates an additional threat of more frequent outbreak events of this dangerous phytophage [13,16-18].

The $D$. sibiricus population long-term dynamics in dark coniferous forests are specific in the following characteristics: outbreaks are rapid, a population reaches its maximum rapidly ( $3-5$ years) and declines equally rapidly ( $2-4$ years). The average duration of an outbreak in dark coniferous forests is ten years. At the stage of mass reproduction, the population density increases more than 500 times. When carrying out aerochemical treatments, the rate of population decline increases sharply [4].

As practice shows, the most common drawback of outbreaks monitoring is their detection delay of 1-2 years [4]. In most cases, emergency insect control measures are taken when a population has reached the eruption phase. Ultimately, this does not always allow saving vast areas of valuable forest ecosystems. Unfortunately, most damaged forests are dead or significantly weakened and have no opportunity to recover in the long term [3-5]. Siberian silk moth outbreaks, along with fires, largely determine the course of succession in taiga forests [2-4]. As a rule, reforestation occurs through a change of species to deciduous stands, which reduces these forest areas' ecosystem and economic functions for a long time.

At present, despite a well-functioning forest pathology monitoring system, a problematic issue of timely decision-making to fight the D. sibiricus lies in modern forest management and its legal framework. The imperfections of the system, which is too complicated and slow, leads to the long-term loss of valuable Siberian forests. Thus, it is advisable to improve the methods aimed at the early detection of $D$. sibiricus outbreaks. An algorithm should be based on the organizational aspects associated with the population reserve territorial features, identified based on the insect ecology understanding using the Earth Observation data. Previous studies have accumulated knowledge that should be used to improve forest pathological monitoring. In Isaev A.S. and Ryapolova V.Ya.'s research, the experience of using an aerospace survey to analyze landscape-ecological confinement of Siberian silk moth outbreaks to certain relief elements is described in detail $[18,19]$.

Successful examples of research related to a retrospective analysis of insect pest outbreaks are shown in the studies of Kharuk V.I., Im S.T., Ranson K.J., Egan J.M., Meddens A.J., and other researchers $[13,15,20-22]$. It is crucial to forecast which pattern the distribution of an outbreak follows, as this process is determined by certain factors and is not always chaotic. Scientific data on this issue is presented in the works of Isaev A.S., 
Lyamtsev N.I., Kondakov Yu.P., Kharuk V.I., Foster J.R., Singh A., Townsend P.A., and others $[2,4,6,13,22-24]$.

Most studies base outbreak forecasting on climatic factors. Earlier observations have repeatedly proved the confinement of insect pest outbreaks to periods of drought and prolonged exposure to high temperatures $[4,16,25]$. From year to year, climatic indicators vary, and, only in the case of a certain temperature and humidity regime, do they act as predictors of an outbreak onset. Climatic factors facilitate the appropriate conditions for an outbreak but do not determine its dynamics. At the same time, a specific orographic base, a platform stable in time and space, characterizes any natural landscape.

The course of an outbreak from its beginning and further chronology is directly related to the site's location relative to the terrain within the natural complex. Therefore, according to the hypothesis put forward, the orographic factor is one of the fundamental predictors of pests living and spreading. The orographic factor is expressed through orographic features-altitude, terrain slope, and slope aspect.

The D. sibiricus phytophage's permanent habitats (reserves) are located within the host-tree range, directly confined to certain relief elements. Thus, the location of reserves is not accidental due to the species' bioecology specificity. Knowledge of a stand's entomoresistance level (identification of stands with low and high resistance to the phytophagous insect) within a specific relief will enable researchers to observe the current state in detail. This is why it is essential to determine parameters for predicting the onset and further development of an outbreak based on the orography. The advantages of a differentiated approach to the organization of background monitoring include the possibility of the early detection of mass defoliation and taking timely measures to prevent an outbreak.

The aim of the present study focused on the parameterization of $D$. sibiricus outbreaks to solve the following issues:

- $\quad$ to reveal the association between an insect outbreak occurrence and certain elements of the relief and analyze the spatiotemporal dynamics of the Siberian silk moth outbreak pattern based on the orographic features of the territory; and

- to assess the prospects for the early detection of Siberian silk moth outbreaks using the known patterns in species ecology and remote sensing methods in mountainous southern taiga forests conditions.

\section{Materials and Methods}

\subsection{Study Area}

The object of the study presents the area (266 thousand hectares) of the recent $D$. sibiricus outbreak within dark coniferous southern mountain taiga forests of the East-Sayan mountains (Krasnoyarsk Krai) (Figure 1). The study area is located in the taiga zone of the Sayan region for forest conservation and belongs to the zone of medium forest pathology threat.

Medium-altitude mountains represent the landscape of the study area. The study site belongs to the South Siberian mountain forest zone and the Altai-Sayan mountains coniferous forest region. The region's climate is sharply continental and influenced by humid western air masses in the summer and the Siberian anticyclone in the winter. The growing season lasts for 149-151 days. The coldest month is January, with the lowest temperature standing at minus $50^{\circ} \mathrm{C}$. The warmest month is July, with the highest temperature of $38.6{ }^{\circ} \mathrm{C}$. The mean annual precipitation is about $527 \mathrm{~mm}$. The prevailing winds blow east-west with a mean wind speed of $2.8-4.7 \mathrm{~m} / \mathrm{s}$ [26].

In the study region, the $D$. sibiricus mostly feeds on Siberian fir (Abies sibirica L.) and Siberian pine (Pinus sibirica Du Tour). The regional dark coniferous formations are dominated by the mossy group, represented by a whole set of forest types [27]. About half $(41.3 \%)$ of the plantations belong to bilberry and bergenia forest types, mainly represented by cedar-fir stands ( $74.5 \%$ of the total area of bilberry and bergenia forest types). The forb-mossy group of plantations accounts for $28.1 \%$. Bilberry-mossy cedar and fir type stands are confined to podzols soils. 


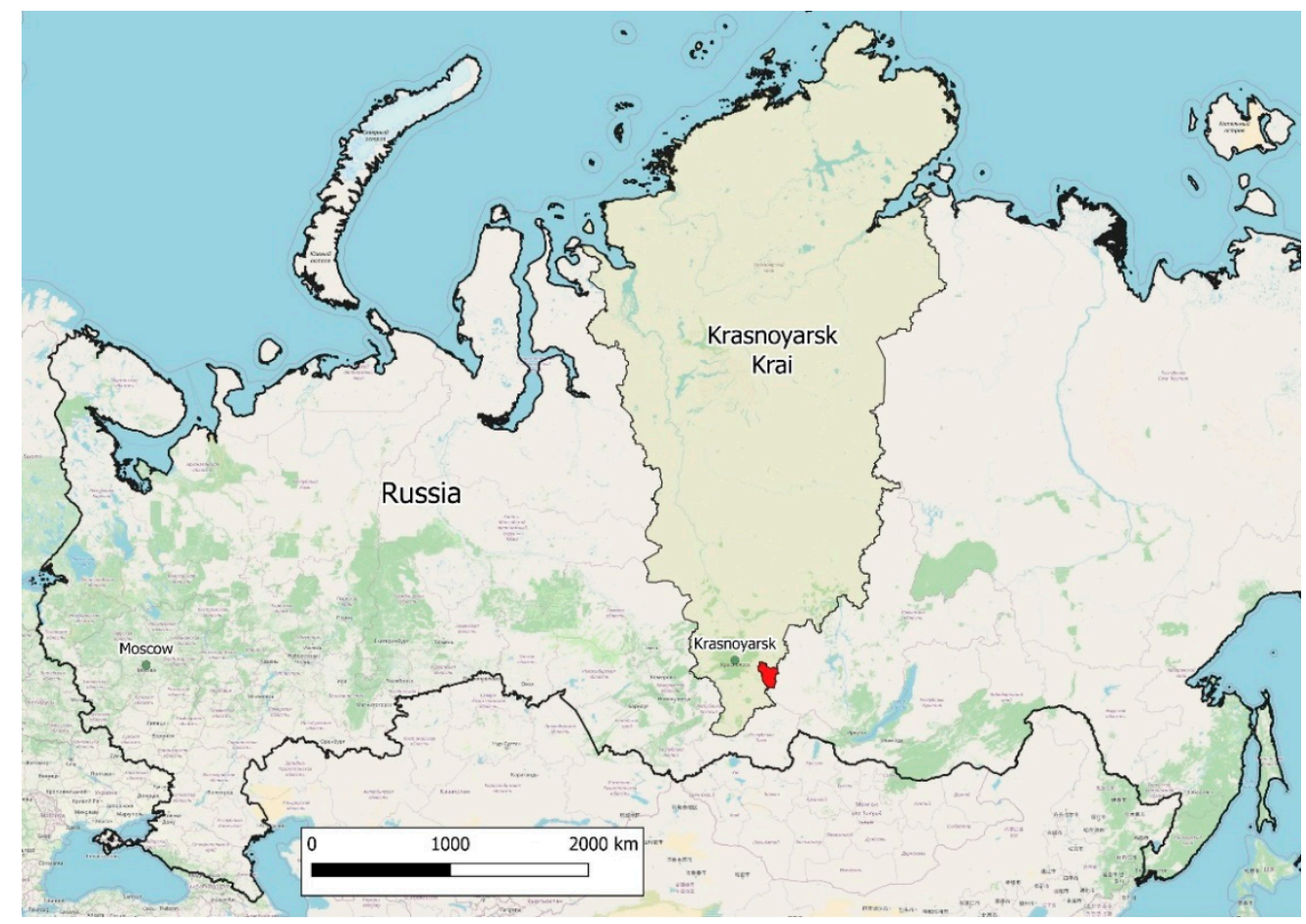

Figure 1. Study area location.

The Bergenia cedar type of forests grows on poorly developed stony soils and mainly on steep slopes. Fir forests are represented by reed grassy and mossy-shrub types of forests and confined to habitats with a favorable combination of heat and humidity. Mossy pine forests occur fragmentarily and locally. Mountain-taiga larch forests are not widespread and are located, like spruce forests, exclusively in hollows and river valleys. Mature and overmature forest stands prevail.

The mean relative density is $0.5-0.7$. In general, the share of such stands of the total area is more than $54.6 \%$. High-density stands are represented mainly by cedar. III-V bonitet classes $(94.6 \%)$ characterize the conditions of forest growth on the territory. High-bonitet plantations are represented by birch and aspen stands. More than $85.0 \%$ of the low-bonitet forests are cedar-fir stands of long-mossy and green-mossy types. High-bonitet birch and aspen stands of the forb group of forest types occupy some areas of the plantations.

\subsection{Satellite Data Collection and Analysis}

The study was carried out by a retrospective analysis based on the geographic information system (GIS) combined with the Earth Observation (EO) data. A Landsat-8 $30 \mathrm{~m}$ Ground Sample Distance (GSD) time-series obtained from the Earth Explorer data portal (https:/ / earthexplorer.usgs.gov/) was used for the analysis. There are well-proven high-precision methods for classifying areas damaged by phytophagous insects using such images in modern studies [13,21,28-30].

Observations on pest outbreak development were conducted from June 2018 to May 2020. Table 1 shows the number of scenes according to satellite images for a specific date, demonstrating the state of the forests before the outbreak and at different damage stages.

The research presents the scenes that most clearly demonstrate the D. sibiricus distribution spatiotemporal dynamics within the study area. The period from 2018 to 2019 was taken for the analysis. The period was limited to 2019, as the D. sibiricus was not functioning during overwintering. Therefore, the situation in the image from 13.05.2020 entirely coincides with the image from 9 September 2019. Figure 2 shows a fragment of the satellite image, including the area of damaged tree stands. The following coordinates limit the site: $54.69600^{\circ} \mathrm{N}, 95.74550^{\circ} \mathrm{W} ; 55.17220^{\circ} \mathrm{N}, 95.34970^{\circ} \mathrm{W} ; 55.17490^{\circ} \mathrm{N}, 96.29150^{\circ} \mathrm{W}$; 
$54.69600^{\circ} \mathrm{N}$, and $96.29120^{\circ} \mathrm{W}$. The Idarskoe Belogorye ridge, located on the Eastern Sayan northeastern macroslope, covered with dark coniferous forest, represents the study area.

Table 1. Observation period.

\begin{tabular}{lc}
\hline \multicolumn{1}{c}{ File Name } & Date \\
\hline LC08_L1TP_141022_20180812_20180815_01_T1 & 25 June 2018 \\
LC08_L1TP_141022_20180929_20181009_01_T1 & 29 September 2018 \\
LC08_L1TP_140022_20190504_20190520_01_T1 & 4 May 2019 \\
LC08_L1TP_141022_20190730_20190801_01_T1 & 30 July 2019 \\
LC08_L1TP_140022_20190909_20190917_01_T1 & 9 September 2019 \\
LC08_L1TP_141022_20200513_20200526_01_T1 & 13 May 2020 \\
\hline
\end{tabular}

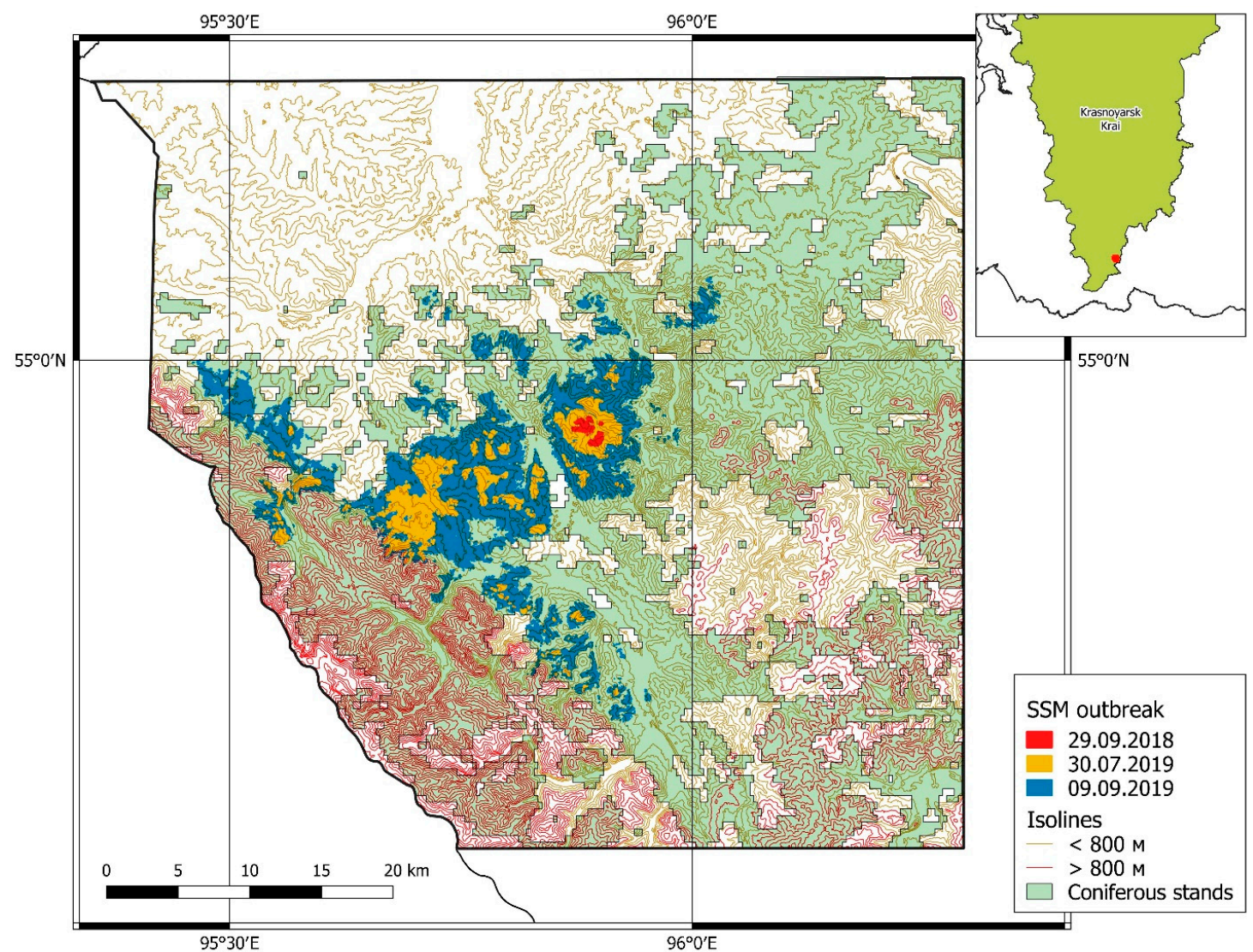

Figure 2. Study area showing the extents from Landsat-8 images, survey polygons of dark coniferous forests damaged by the Siberian silk moth. Legend: red, yellow, and blue backgrounds show the areas of forest stands damaged by the pest (defoliation of 50\% or more) on a specific date-29 September 2018, 30 July 2019, 9 September 2019, respectively; green background-areas occupied by coniferous plantations (potential host-trees of the pest); the relief in the form of brown isolines is shown at altitudes up to $800 \mathrm{~m}$, red lines-at an altitude of more than $800 \mathrm{~m}$.

A sharply dissected erosional medium-altitude mountain relief with steep and prolonged mountain slopes, which often end as a river-cut cliff, dominates the territory. The mean height above sea level ranges from 470 to $1200 \mathrm{~m}$. The degree of the slopes varies from 10 to 25 degrees, often reaching 40 degrees [27]. In the northern part of the study area, deciduous and light coniferous stands occupy relief elements. Wetlands are formed in depressions in the surface, which excludes this territory from the area of potential $D$. sibiricus distribution. Cedar and fir stands occur at higher elevations and are concentrated in the site's central and southern parts. 
EO data processing was carried out in the R program (v4.0.2) [31]. This is a free software environment for statistical computing and graphics. Visual analysis of the EO data was carried out using the QGIS program (v3.10) (https:/ / qgis.org).

At the preparatory stage, a visual analysis of the areas damaged by the Siberian silk moth was carried out. Landsat-8 satellite images for 29 September 2018, 30 July 2019, and 9 September 2019 were the primary data source. Processing level L2 images were obtained from the U.S (Geological Survey website: (https:/ / earthexplorer.usgs.gov/)). Clouds and cloud shadows were removed from the imagery during data preparation. The same date's images were glued together and re-projected into the WGS84 geographic coordinate system for complete coverage of the study area.

For better visibility of the damage, the following combination of channels was used: red-channel 7; green-channel 5; and blue-channel 3. With this channel combination, areas damaged by the Siberian silk moth were displayed in crimson, dark-coniferous stands in dark green, and deciduous and light-coniferous stands in light green. This remote sensing method made it possible to identify stands damaged by the phytophage. Later, this correspondence was established during field surveys of the territory (see Section 2.3).

Two popular classification algorithms were used to create a mask for damaged stands: random forest [32] and xgBoost [33], implemented in the caret package [34] for the R language. The classification aimed to divide each image's pixels into two classes-stands damaged by D. sibiricus, and the rest. Areas of both types were indicated on the images based on EO data visual assessment. A sample was formed from the selected polygons, which were divided into training and testing (a proportion of 75/25, respectively). EO data channels 1 to 7 with a spatial resolution of $30 \mathrm{~m}$ were included in the classification. The parameters of the classifier were selected separately for the setting by maximizing each Kappa measure. Cross-validation (cv) dividing the training sample seven-fold was used to search for hyper parameters. The result was two xgBoost models and one random forest model. The classification accuracy is presented in the form of standard statistical indicators in Table 2.

Table 2. Statistical indicators of the algorithms.

\begin{tabular}{ccccccc}
\hline Date & $\begin{array}{c}\text { Damaged Area, } \\
\text { Ha }\end{array}$ & $\begin{array}{c}\text { Classification } \\
\text { Algorithm }\end{array}$ & Accuracy & Sensitivity & Specificity & Kappa \\
\hline 29 September 2018 & 109.7 & xgboost & 1.000 & 1.000 & 0.886 & 0.918 \\
30 July 2019 & 3459.6 & xgboost & 0.998 & 0.999 & 0.988 & 0.981 \\
9 September 2019 & 17603.3 & random forest & 1.000 & 1.000 & 1.000 & 0.999 \\
\hline
\end{tabular}

As a result of tuning the models, the following parameters were obtained: 29 September 2018 (xgboost: nrounds $=600$, max_depth $=20$, eta $=0.1$, gamma $=0$, colsample_bytree $=0.9$, min_child_weight $=1$, and subsample $=1) ; 30$ July 2019 (xgboost: nrounds $=900$, max_depth $=5$, eta $=0.1$, gamma $=0$, colsample_bytree $=0.9$, min_child_weight $=1$, and subsample $=1$ ); 9 September 2019 (random forest: $\operatorname{mtry}=4$ and ntree $=500$ ).

For XGBoost: nrounds—number of trees to grow; max_depth-max depth of the tree; eta-control of the learning rate; gamma-control regularization (gamma $=0$ means no regularization); colsample_bytree-control the number of features (variables) supplied to a tree; min_child_weight_-if the leaf node has a minimum sum of instance weight (calculated by second-order partial derivative) lower than min_child_weight, the tree splitting stops; subsample-controls the number of samples (observations) supplied to a tree. For random forest: mtry - the number of variables is randomly collected to be sampled at each split time; ntree- the number of branches to grow after each time split.

The resulting masks of damaged stands were used to extract the orographic characteristics of the area. The ASTER GDEM (Advanced Spaceborne Thermal Emission and Reflection Radiometer Global Digital Elevation Model) v3 product (https: / /pdaac.usgs. gov/news/nasa-and-meti-release-aster-global-dem-version-3/) was used as the basis for obtaining the characteristics of the relief. The spatial resolution of the digital elevation 
model was $30 \mathrm{~m}$; the coordinate system was WGS84. The slopes' exposure and degree were calculated using standard methods in the raster package [35] and the terrain function was included in it. Eight neighboring cells of the raster were used to calculate these parameters.

For slopes of more than 5 degrees, the exposure from the azimuth was transformed into the names of the cardinal points in the following intervals: $\mathrm{N}[337.5 ; 360),[0 ; 22.5)$; NE [22.5; 67.5); E [67.5; 112.5); SE [112.5; 157.5); S [157.5; 202.5); SW [202.5; 247.5); W [247.5; 292.5); and NW [292.5; 337.5). The terrain characteristics, which included the altitude, terrain slope, and slope aspect, were extracted from the damage mask for each date and converted into a data table that was analyzed using standard descriptive statistics methods. Statistical indicators of the distribution density were measured by the number of pixels.

Before starting the analysis, pixels related to damage at an altitude of more than $1000 \mathrm{~m}$ were regarded as random classification errors and removed from the data. Such a methodological approach was based on the available scientific information and our conclusions obtained from EO data processing. According to the scientific data, in the Altai-Sayan ecoregion forests, the highest pest density is observed at lower elevations. As a population moves up, its density decreases. The $D$. sibiricus population in the study region reaches 800-900 m above sea level and is rarely encountered at higher altitudes [4]. According to other researchers $[13,18,36,37]$, global warming changes pest's ecology, facilitating elevation range expansion.

Potentially, this phenomenon was also considered in the analysis. However, when processing EO data, a clear boundary of the outbreak distribution at an altitude of up to $1000 \mathrm{~m}$ was revealed. Damages to forest stands by D. sibiricus above this altitude were removed from the set of analyzed data as classification errors. In total, 93 pixels were removed, which was 5.08 ha (0.82 ha for 30 July 2019 and 4.26 ha for 9 September 2019). When determining the area of damaged forest, stands subjected to cutting and forest fires were excluded. The classification algorithm somewhat underestimates damaged areas because it does not measure small damage to plantations located mainly at the outbreak's edges.

The analysis considered only the increase in forest territory damaged by the D. sibiricus. For example, areas damaged on 30 July 2019, did not include the damage detected earlier. The same is true for damage to 9 September 2019. Such an approach allows analyzing only the forest canopy damage identified between the current and previous dates.

The determination of specific features of the plant damage locations, considering the peculiarities of orography, was carried out using the digital elevation model ASTER Global DEM Version 3 (https: / / lpdaac.usgs.gov/news/nasa-and-meti-release-aster-global-demversion-3/). The following layers of relief were used in the classification: height above mean sea level, slope exposure, and degree of slopes.

For analysis of the slope exposure, each exposure's damaged areas are expressed as a percentage of the total area of coniferous stands potentially included in the damaged zone, growing at this exposure. This ensures consideration of the factor of uneven distribution of food supply across slope exposures. The host-plant range was identified based on classified MODIS (Moderate-resolution Imaging Spectroradiometer) images [38] (MCD12Q1 v006) for 2017 with a spatial resolution of $500 \mathrm{~m}$. The classification was based on the IGBP (International Geosphere-Biosphere Program) algorithm [39]. Pixels classified as an area covered by trees and more than $60 \%$ dominated by evergreen conifers or larch (I and III classes) were considered the host-plant range. The total area occupied by conifer plantations was 144,353.7 hectares. In all cases, exposures were calculated for slopes with an angle more than or equal to 5 degrees.

\subsection{On-Ground Studies}

According to forest pathologists of the Krasnoyarsk Center of Forest protection, the population's transition to the outbreak stage took place in the spring of 2019. The outbreak was facilitated by insufficient water supply during the growing season of 2015 and June, July, and September 2016. Notably, the daily mean air temperature was high during this period. As a result, favorable climatic conditions provoked the appearance of females with 
high fecundity in 2017 and pest population growth. At the time of the outbreak (September 2019), individuals of the third and fourth instars dominated the D. sibiricus population. The number of fifth and sixth instar larvae was up to $8 \%$. Consequently, in the fall of 2018, larvae overwintered primarily in the second and third instars. The population density ranged between 219 and 2187 number of individuals per one model tree (MT). There were no larvae noted as sick or infested with parasites.

The EO data was verified during field surveys to visually assess the extent of the damage to trees caused by the D. sibiricus larvae. Field studies were conducted during MayJune. The assessment was carried out using the method of laying out sample plots. The experimental sites were located at the following coordinates: No. $1-55.06699^{\circ} \mathrm{N}, 95.99062^{\circ}$ W; No. 2-55.05004 ${ }^{\circ}$ N, $95.93655^{\circ}$ W; No. 3-55.01668 ${ }^{\circ}$ N, $96.00512^{\circ}$ W; No. 4-55.01856 ${ }^{\circ}$ N, $96.03052^{\circ} \mathrm{W}$; No. $5-55.02222^{\circ} \mathrm{N}, 96.02028^{\circ} \mathrm{W}$; and No. 6-55.02589 ${ }^{\circ} \mathrm{N}, 96.03745^{\circ}$ $\mathrm{W}$. Within a sample plot, a complete enumeration of trees was carried out estimating the crown damage percentage.

Caterpillars were collected by striking the trunks of randomly selected model trees (five pieces on each sample plot), and their number was counted. In general, defoliation of the surveyed plantations ranged from $5-100 \%$. According to remote sensing, the highest tree crown defoliation level was observed in forest areas where on-ground studies indicate lower indices of the pest density (from a few individuals to 129 individuals per MT). At the time of observation, this fact indicates a possible pest migration to nearby territories.

\section{Results}

In mountainous conditions, the distribution of the D. sibiricus depends on the height of a slope.

Figure 3 presents the spatial characteristics of the damaged plantations' location, depending on the height above sea level within the study area.

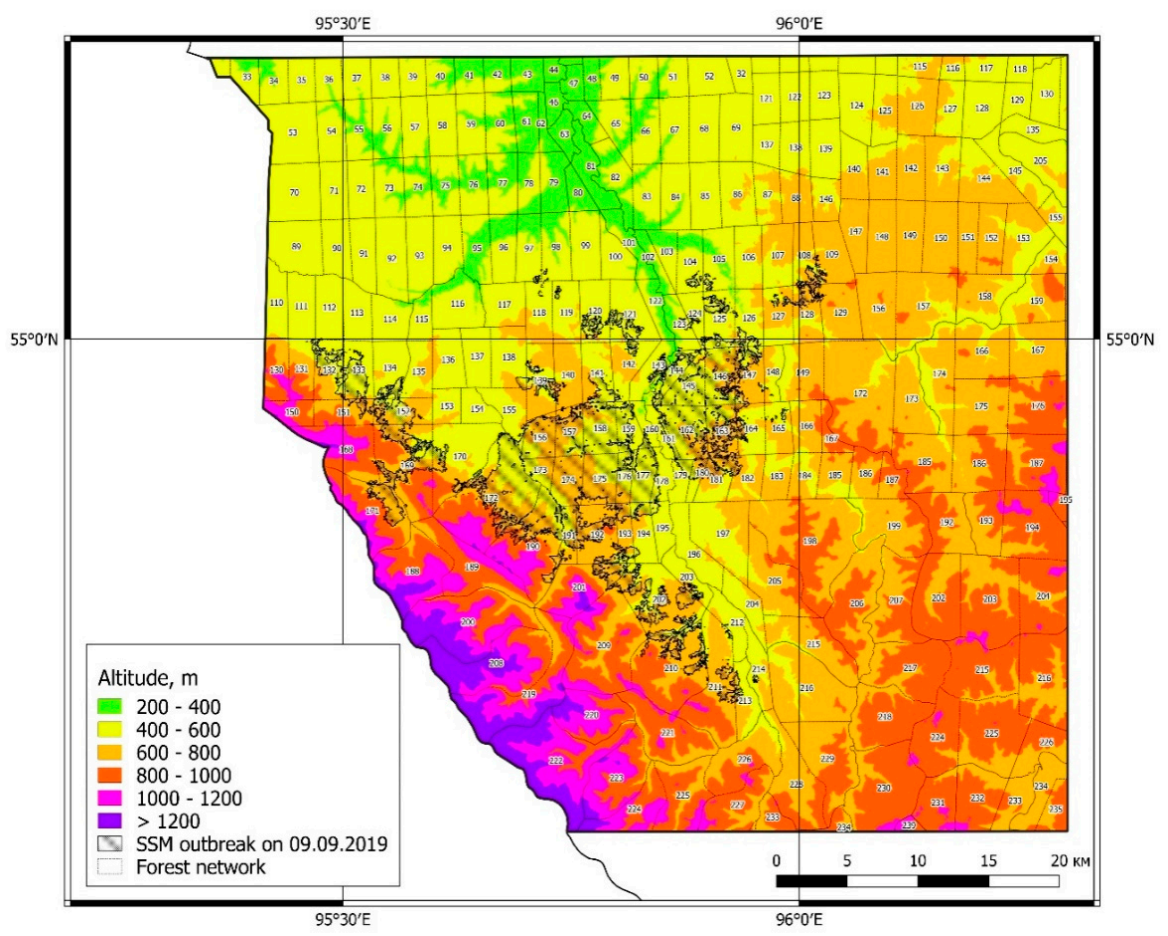

Figure 3. A digital elevation model representing the areas of dark coniferous stands damaged by the Siberian silk moth, depending on the height above sea level. Legend: green background-areas located at an altitude of 200 to $400 \mathrm{~m}$, yellowfrom 400 to $600 \mathrm{~m}$, orange-from 600 to $800 \mathrm{~m}$, red—from 800 to $1000 \mathrm{~m}$, pink—from 1000. to $1200 \mathrm{~m}$, blue-more than $1200 \mathrm{~m}$; and black shading - boundaries of the forest defoliated during the outbreak as of 9 September 2019. 
Figure 4 clearly shows the spatiotemporal dynamics of the distribution of damaged plantings depending on altitude.

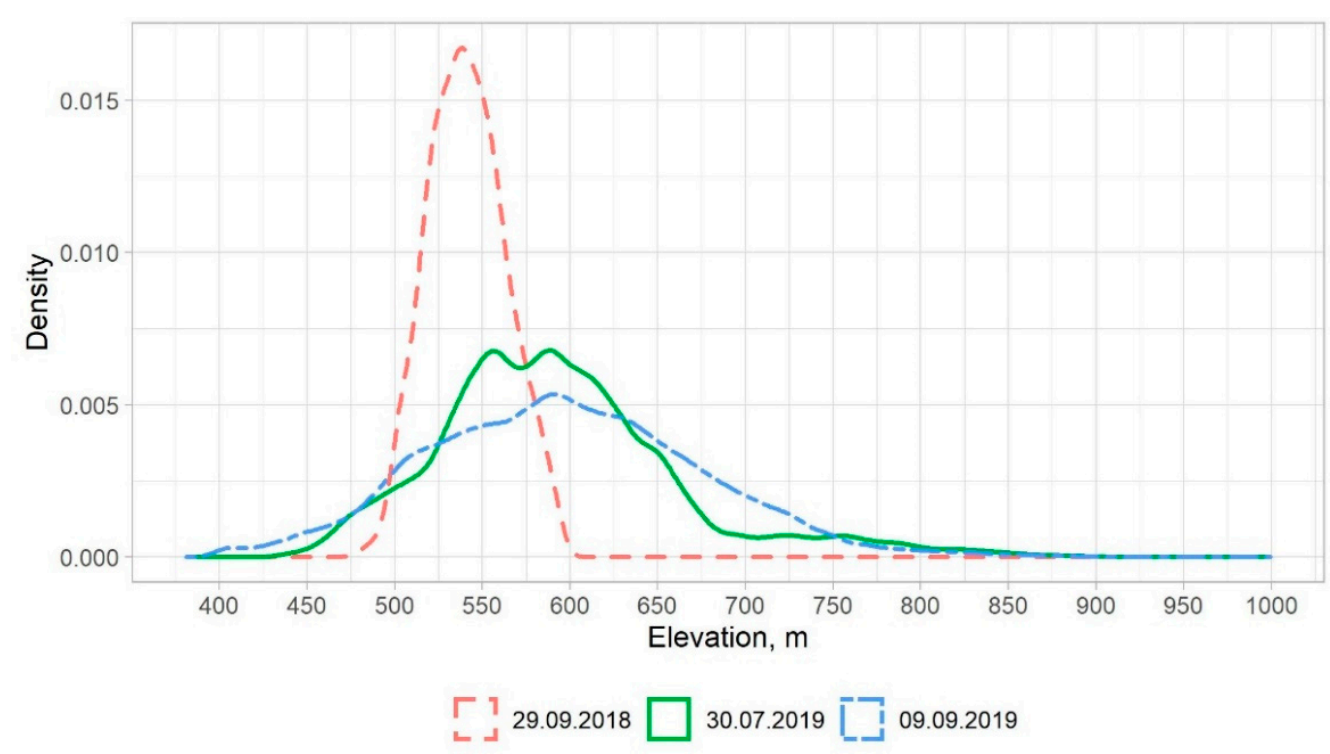

Figure 4. Spatiotemporal dynamics of the damaged plantings considering the height above sea level.

The graph shows that the median values of the altitude of tree damage in 2018 were lower than in subsequent periods. The range of variation of damage depending on altitude increased over time. The distribution of random variables appears to be approximately normal. Table 3 gives descriptive statistics of the distributions.

Table 3. Statistical indicators of the distribution of damaged forest stands by height above sea level.

\begin{tabular}{|c|c|c|c|c|c|c|c|c|c|c|c|c|c|}
\hline \multirow{2}{*}{ Date } & \multirow{2}{*}{$\begin{array}{c}\text { Area } \\
\text { Increase, } \\
\text { Ha }\end{array}$} & \multicolumn{3}{|c|}{ Altitude, m } & \multicolumn{9}{|c|}{ Percentiles } \\
\hline & & Average & Max. & Min. & 0.1 & 0.5 & 2.5 & 25 & 50 & 75 & 97.5 & 99.5 & 99.9 \\
\hline 29 September 2018 & 109.7 & 541.1 & 596.2 & 478.3 & 481 & 491 & 501 & 525 & 540 & 557 & 586 & 592 & 596 \\
\hline 30 July 2019 & 3349.9 & 593.2 & 999.3 & 429.2 & 441 & 457 & 477 & 547 & 586 & 627 & 779 & 843 & 883 \\
\hline 9 September 2019 & 14253.4 & 597.0 & 997.9 & 381.1 & 400 & 412 & 452 & 541 & 594 & 648 & 757 & 833 & 884 \\
\hline
\end{tabular}

Initial areas of sharp pest population growth were located at an altitude from 480 to $600 \mathrm{~m}$ above sea level. In July of the next growing season, the area of damaged forest stands increased by 29 times. Outbreaks were observed in the range from $430 \mathrm{~m}$ and reached an altitude of $883 \mathrm{~m}$ above sea level in $99.9 \%$ of cases. By September, the area of damage increased by another 4.4 times. In the mountainous part, the D. sibiricus outbreak distribution was limited by foothills of the ridge's northeastern slope and formed a long line with individual areas of local damage in the flattened terrain (Figure 2).

The maximum elevation where stands defoliated by the $D$. sibiricus were found was $884 \mathrm{~m}$ above sea level, making a proportion of less than $0.5 \%$ of the total damaged area. Consequently, when predicting the development of Siberian silk moth outbreak for a given landscape condition, this factor should cover extreme points of the range from 400 to $900 \mathrm{~m}$. To detect the pest population's activation early, one should focus on monitoring areas of dark coniferous forests at altitudes from 400 to $600 \mathrm{~m}$.

Next, at the level of a given terrain, the possibility of identifying and understanding the natural structure of outbreaks onset places (the D. sibiricus reserves) was considered.

Figure 5 presents the dynamics of the distribution of areas damaged by D. sibiricus, depending on the terrain slope. 


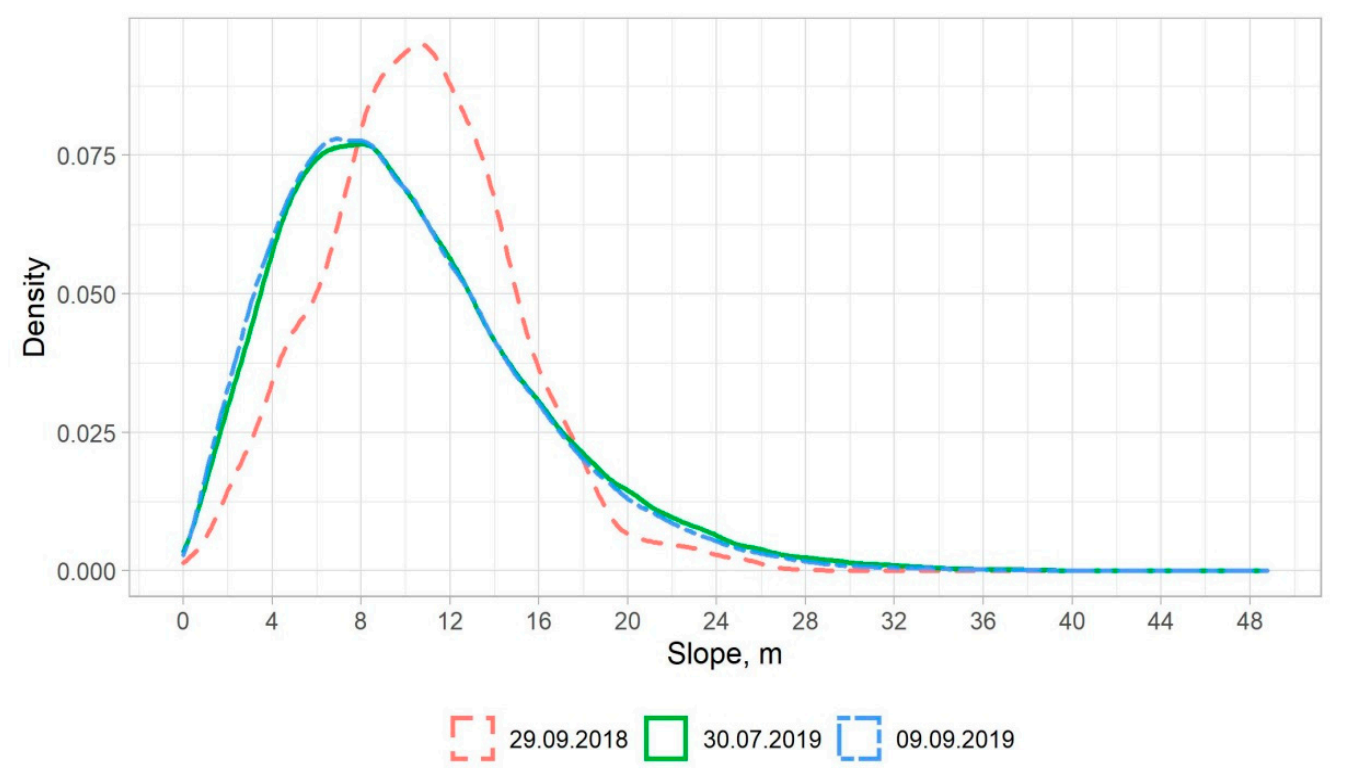

Figure 5. Distribution of damaged forest stands areas, depending on the terrain slope.

At the initial stage of outbreak development, the graph shows the concentration of damage sites on slopes from 8 to 14 degrees. In subsequent periods, the graphic lines shift to the left, to less steep slopes, and the concentration shifted 4 degrees, which characterizes the outbreak development process. From 30 July 2019 to 9 September 2019, damage zones associated with the slope steepness retained their general dynamics. During this period, damaged plantations were increasing, and insects were moving from reserve zones.

Insect outbreaks drive competitive relations, which increase the migratory activity of individuals. Therefore, if there is a food supply in nearby areas, pests move to more steep slopes. The pest's concentration and migration areas were mainly concentrated on gentle terrains and slopes up to 15 degrees. During field surveys of the damaged territory, the pattern of larval feeding was revealed. In mid-altitude mountains, larvae fed on needles from trees on the tops and middle parts of the slopes, avoiding lower areas due to higher humidity and cold microclimatic conditions.

The graphically obtained results were confirmed by statistical characteristics of the distribution of areas regarding this feature, presented in Table 4.

Table 4. Statistical indicators of the distribution of damaged forest stands by terrain slope.

\begin{tabular}{|c|c|c|c|c|c|c|c|c|c|c|c|}
\hline \multirow{2}{*}{ Date } & \multicolumn{4}{|c|}{ Terrain Slope, Degrees } & \multicolumn{7}{|c|}{ Percentiles } \\
\hline & Average & Median & Max. & Min. & 0.5 & 2.5 & 25 & 50 & 75 & 97.5 & 99.5 \\
\hline 29 September 2018 & 10.6 & 10.6 & 27.8 & 0.1 & 1.5 & 2.7 & 7.8 & 10.6 & 13.3 & 19.7 & 24.2 \\
\hline 30 July 2019 & 10.2 & 9.2 & 45.1 & 0.1 & 0.8 & 1.8 & 5.9 & 9.2 & 13.3 & 24.0 & 30.5 \\
\hline 9 September 2019 & 9.9 & 9.0 & 48.8 & 0.0 & 0.8 & 1.7 & 5.8 & 9.0 & 13.0 & 23.0 & 28.7 \\
\hline
\end{tabular}

Damaged stands are mostly located on terrains with a slope angle of about 10 degrees, both in terms of the mean and median values. In $75 \%$ of cases during all observation periods, the outbreak spread predominantly in stands located on slopes of up to 13 degrees, sporadically reaching steep slopes of 30 degrees.

Figure 6 shows the damaged area dynamics according to slope aspect differences at the specified date. The area increase value is expressed as a percentage of the coniferous stands total area stands on a particular slope aspect. Table 5 represents the statistical indicators of these distributions. 

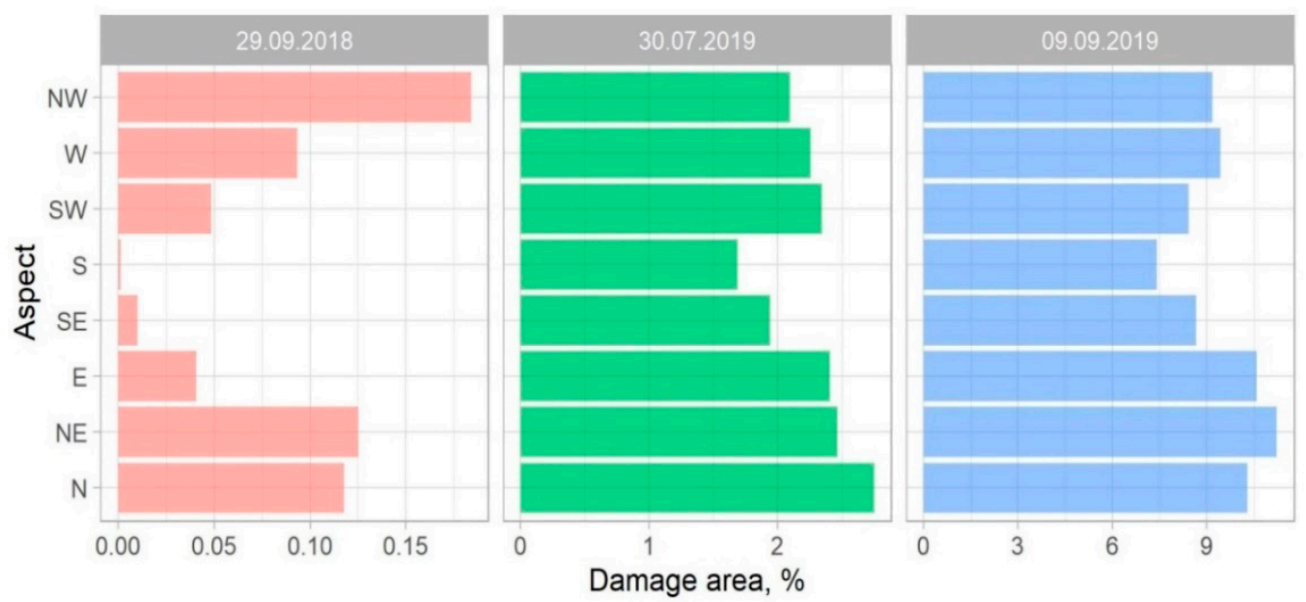

Figure 6. Dynamics of the area increase (\%) of damaged dark coniferous stands depending on the slope aspect at a specific date.

Table 5. Statistical indicators of damaged stand distribution depending on the slope aspect.

\begin{tabular}{ccccccccc}
\hline Date & NW & W & SW & S & SE & E & NE & N \\
\hline 29 September 2018 & 0.18 & 0.09 & 0.05 & 0.00 & 0.01 & 0.04 & 0.13 & 0.12 \\
30 July 2019 & 2.10 & 2.26 & 2.34 & 1.69 & 1.94 & 2.41 & 2.47 & 2.75 \\
9 September 2019 & 9.18 & 9.42 & 8.42 & 7.42 & 8.66 & 10.58 & 11.22 & 10.28 \\
\hline
\end{tabular}

The results show that the largest damaged areas recorded at the beginning of the outbreak cycle were located at the northern, northeastern, northwestern, and eastern slopes. This trend continued in subsequent periods. Empirically, this fact is related to the experimental site's location on the Eastern Sayan northeastern macroslope.

The silvicultural characteristics of the forest area, where remote sensing indicated early signs of tree crown defoliation by the phytophage, were analyzed (Table 6). The analysis clarified the confinement pattern of various forest types to certain relief elements in places of the D. sibiricus outbreak onset.

Table 6. The confinement of forest types of dark coniferous plant formations to certain relief elements within the forest area, initially damaged by D. sibiricus (the period from.29 September 2018 to 30 July 2019).

\begin{tabular}{|c|c|c|c|c|c|c|c|c|c|c|c|c|c|c|c|c|}
\hline \multirow{3}{*}{ Forest Type ${ }^{1}$} & \multicolumn{16}{|c|}{ Aspect and Degree of Slopes } \\
\hline & \multicolumn{2}{|c|}{$\mathbf{N}$} & \multicolumn{2}{|c|}{ NE } & \multicolumn{2}{|c|}{ NW } & \multicolumn{2}{|c|}{$S$} & \multicolumn{2}{|c|}{ SE } & \multicolumn{2}{|c|}{ SW } & \multicolumn{2}{|c|}{$\mathbf{E}$} & \multicolumn{2}{|c|}{ W } \\
\hline & $\begin{array}{l}\text { Up to } \\
10^{\circ}\end{array}$ & $>10^{\circ}$ & $\begin{array}{l}\text { Up to } \\
10^{\circ}\end{array}$ & $>10^{\circ}$ & $\begin{array}{l}\text { Up to } \\
10^{\circ}\end{array}$ & $>10^{\circ}$ & $\begin{array}{l}\text { Up to } \\
10^{\circ}\end{array}$ & $>10^{\circ}$ & $\begin{array}{l}\text { Up to } \\
10^{\circ}\end{array}$ & $>10^{\circ}$ & $\begin{array}{l}\text { Up to } \\
10^{\circ}\end{array}$ & $>10^{\circ}$ & $\begin{array}{l}\text { Up to } \\
10^{\circ}\end{array}$ & $>10^{\circ}$ & $\underset{10^{\circ}}{\text { Up to }}$ & $>10^{\circ}$ \\
\hline Bil.ced & +2 & - & + & - & + & - & - & - & - & - & - & - & + & - & + & + \\
\hline Ber.ced & + & +++ & - & + & - & + & ++ & + & + & - & + & + & + & + & + & +++ \\
\hline Bil.fir & ++ & - & - & - & - & - & + & + & ++ & + & + & - & - & - & + & - \\
\hline Mos.fir & - & + & ++ & + & + & + & + & + & - & + & - & + & + & + & + & - \\
\hline Ber.fir & - & + & - & - & - & - & - & & & & & & + & & ++ & + \\
\hline
\end{tabular}

${ }^{1}$ Bil.ced—bilberry cedar forest, Ber.ced—bergenia cedar forest, Bil.fir—bilberry fir forest, Mos.fir—mossy fir forest, Ber.fir—bergenia fir forest; ${ }^{2}(+)$-frequency up to $5 \%,(++)$-from $5-10 \%$, and $(+++)$ - more than $10 \%$.

A detailed analysis of the initial outbreak showed that damaged stands were represented mainly by mossy fir forests, occupying the entire spectrum of exposures on gentle terrains and slopes up to 15 degrees. Bilberry cedar forests were widely represented on gentle slopes with northerly, westerly, and easterly aspects. Bilberry fir forests were mainly concentrated on south-facing slopes. We concluded that the listed forest areas are recommended to be attributed to territories of low entomoresistance, and thus they should be considered as reserves of the Siberian silk moth when predicting an outbreak.

Considering the outbreak development in general (Figure 5), the north-facing slope dominance smoothed over time since, due to larvae migration, the damaged area included 
nearby dark coniferous forests of the forb group of forest types located on slopes with various aspects. Mostly, these were bergenia cedar forests on steep slopes and reed grassy fir forests growing on flattened terrains and south-facing slopes. Hypothetically, within the study area, these plantations are not areas of the outbreak onset. However, when predicting an outbreak's spatial development, these stands should be attributed to the zone of subsequent (secondary) damage, which will be caused by the larvae migration from the reserves.

\section{Discussion}

Theoretically, the mountain taiga landscape's orography features determine the $D$. sibiricus outbreak development's spatiotemporal dynamics mainly by two factors-the phytophagous insect host-plant range and temperature and humidity regime of specific areas. Long-term observations have proven that all $D$. sibiricus outbreaks are concentrated on podzolic soils of mountainous regions. This coincidence expresses the silk moth's confinement to elevated parts of the relief, mainly to mountain ranges and plateaus. On the other hand, this pattern is associated with the pests' food plant distribution on these soils [14]. At the same time, $D$. sibiricus prefers warm habitats $[3,4,6]$, so, as a rule, the pests concentration is confined to well-warmed places. A favorable temperature regime is a fundamental criterion for determining the potential range of this pest's spread $[3,5,19]$.

Dark coniferous formations within the study area were concentrated at the median height of $687 \mathrm{~m}$ above sea level. The onset of outbreak development was also confined to this altitude range. The share of $99 \%$ of the stands was located at an altitude of $397-1289 \mathrm{~m}$. Thus, the upper limit of the Siberian silk moth's food supply was much higher than $900 \mathrm{~m}$ (this is the maximum altitude at which damage was detected). Therefore, the limit of damage depending on altitude was not associated with the food supply. At the same time, according to Yu. P. Kondakov [4], the upper limit of the D. sibiricus outbreak distribution at absolute altitudes of $800-900 \mathrm{~m}$ in mountainous southern taiga forests was associated with limiting climatic factors-long-term indicators of the sum of active temperatures $1200{ }^{\circ} \mathrm{C}$ and moisture coefficient of 2.0 (according to V. S. Mezentsev) [40].

Analysis of the $D$. sibiricus outbreak spatial distribution should consider the patterns of its ecological association with particular landscape elements $[15,16,18]$. The natural structure of places where an outbreak begins is essential. Complex indicators of the relief that allow for the prediction of pest reserve locations are the slope angle and exposure, combining to form the most favorable microclimatic conditions for a pest outbreak.

There are two factors determining the ground surface temperature in the mountains. The first is the aspect of the slope, which determines the energy resources of the habitat. The second factor is the position on the slope, which regulates the soil moisture reserves. Most of the previous studies mentioned that south-facing slopes were favorable for the $D$. sibiricus reserves due to greater insolation and higher ground surface temperature $[3,5,6,13,19,20]$. Such areas of dark coniferous forests are characterized by the most drained and warm conditions, where trees are growing on loose, relatively fresh, and porous soddy-podzolic soils with no signs of gleying [27]. Earlier melting of snow cover and later autumn frosts than on other forms of relief are observed at these areas, which prolong the larvae foliagefeeding period.

The soil aeration and hydrothermal regime, as well as the thickness of the litter layer, determine the best conditions for the wintering of $D$. sibiricus larvae in the study area $[3,19]$. However, in the given orographic landscape conditions, the opposite situation was revealed. The onset of damage and further development of the outbreak took place at slopes with northerly aspects. Regarding the location of the study area, this fact can be explained by the humidity conditions. In such conditions, the slopes with different aspects were less contrasting in terms of the heat and moisture supply.

The vegetation type or groups of formations remain unchanged, and differences appeared at the level of productivity and groups of forest types [26,27]. Therefore, under a given area's conditions, the slope exposure cannot act as a direct reference when predicting 
potential phytophage habitats. It is recommended to take the relief, including a particular type of forest and slope steepness, as the basic criterion. The initial hosting objects were cedar and fir forest stands of the mossy group of forest types located on gentle terrains and slopes of up to 15 degrees.

The mossy forest floor's temperature and humidity regime created the most favorable conditions for the Siberian silk moth development. Siberian silk moth larvae prefer to overwinter under the moss litter at a depth of $20 \mathrm{~cm}$ from the surface [3,5]. The clarification and adjustment of these area boundaries, considering the slope exposure, can be carried out in frames of field surveys. D. sibiricus avoids forest areas on steep erosional slopes and thin soils as well as wet and cold habitats, which typically form in lower-relief areas [3,5,19].

In the study area, the bergenia type of forest grows on poorly developed stony soils and mainly on steep slopes, so these cannot be areas of an outbreak onset. A specific pattern of a lesser proportion of damage to stands located in depressions was revealed during field surveys. Fir forests of the forb group of forest types were also characterized by late damage. The obtained results support the previous information on the pest outbreak's occurrence and spread in mid-altitude mountains. Thus, the present study results can act as parameters in the development of forecast models for the study area conditions.

The probabilistic forecasting of the $D$. sibiricus outbreak distribution in a specific terrain depends on certain other factors, more often associated with the silvicultural characteristics of forest stands. Defoliated forest areas are represented as irregular peripheral circles girding the outbreak epicenter with vast quantities of dead trees. Insect pest outbreaks spread from the center to the periphery as a damped wave- the farther from the core, the less the intensity of damage to forest stands [4]. An admixture of deciduous species negatively affects the dispersal of $D$. sibiricus.

Large areas of birch stands near the outbreak (with a proportion of six or more units) stop the spread of the pests completely [5]. As for the study area, such territories within the range of host plants were located at the upper limit of the outbreak spread, where little damage was observed, mainly limited by areas of birch-aspen stands. In other cases, deciduous forests growing in dark coniferous forests occupied an insignificant territory. Therefore, they could not provide a mosaic structure of the host-tree range, which could be a significant obstacle to the pest's migration to nearby forests.

Stand density does not play a significant role in the pest's dispersal, except for lowdensity stands, since the distance between trees is vital for larvae crawling. The most intense damage is often observed in forest stands with a relative density of 0.5-0.7 [5]. As for the study area, damaged sites included stands with a relative density of up to 0.8 .

Researchers have indicated a nutritional selectivity of the pests $[5,14]$. For instance, the Siberian spruce needles are less attractive for $D$. sibiricus [12]. The presence of spruce in the forest composition is an indicator of unfavorable conditions for pest development. According to A.S. Isaev, in heavily damaged stands, the share of spruce in the forest composition does not exceed one unit (10\%); at high values, the damage is reduced [18]. P.P. Okunev revealed, as a characteristic feature of the study area, the least degree of damage to Scots pine compared to other conifers [14].

The influence of the factors mentioned above on the larvae migratory ability in mountainous terrain requires additional studies aimed to provide an integrated approach in forecasting and monitoring the outbreak development within a particular area.

\section{Conclusions}

D. sibiricus permanently inhabits forest ecosystems in mountainous southern taiga, posing a constant threat of damage. Identifying the behavioral ecology of the phytophagous insect population in mountainous terrain opens up opportunities for improving monitoring systems and applying a digital elevation model to predict an outbreak's spread. This type of monitoring allows for the timely implementation of active forest protection measures. This is also important for the remaining fir and cedar forests near the studied 
defoliated areas, which continue to retain valuable biodiversity, being of great ecological and economic importance.

The study revealed specific Siberian silk moth distribution patterns aimed at detailing the preliminary observation zones in mountainous terrain. Background monitoring locations should be concentrated on dark coniferous forests covering altitude levels from 400 to $600 \mathrm{~m}$ with a potential distribution area of up to $900 \mathrm{~m}$. Outbreak areas (reserves) may be located on gentle terrains and slopes of 10 to 15 degrees, excluding wet habitats and depressions. The pests prefer mossy forest floor, which is equally spread on slopes of both northern and southern exposures in mountain southern taiga forests.

Thus, the observation spectrum should include all areas of this forest type considering the above parameters. Based on the previous observations, south-facing slopes are assumed to be priority areas for reserves. The study results can serve as the basis for the parameterization of discrete data for mid-altitude mountain conditions when modeling the forecast of $D$. sibiricus outbreaks with the further possibility of extrapolating the revealed patterns to similar territories.

Author Contributions: Formal analysis, S.M.S., D.A.D., S.S.K., and A.A.G.; investigation, S.M.S., S.V.V., V.A.I., and P.V.M.; methodology, S.M.S. and A.A.G.; writing—original draft, S.M.S.; writingreview \& editing, S.M.S. and P.V.M. All authors have read and agreed to the published version of the manuscript.

Funding: The research was carried out within the projects "Fundamentals of forest protection from entomo- and fittings pests in Siberia" (№ FEFE-2020-0014) within the framework of the state assignment, set out by the Ministry of Education and Science of the Russian Federation, for the implementation by the Scientific Laboratory of Forest Health.

Institutional Review Board Statement: Not applicable.

Informed Consent Statement: Not applicable.

Data Availability Statement: The data presented in this study are available on request from the corresponding author.

Acknowledgments: We would like to thank the Krasnoyarsk center for the collective use of the Federal research center of the Siberian branch of the Russian Academy of Sciences for the equipment provided. The authors acknowledge the editor and the anonymous reviewers for their comments that helped us to improve the manuscript.

Conflicts of Interest: The authors declare no conflict of interest. The funders had no role in the design of the study; in the collection, analyses, or interpretation of data; in the writing of the manuscript; or in the decision to publish the results.

\section{References}

1. Global Invasive Species Database. 2020. Available online: http://www.iucngisd.org/gisd/search.php (accessed on 10 December 2020).

2. Isaev, A.S.; Palnikova, E.N.; Sukhovolsky, V.G.; Tarasova, O.V. Population Dynamics of Defoliating Forest Insects: Models and Forecasts; KMK Scientific Press Ltd.: Moscow, Russia, 2015; p. 262.

3. Rozhkov, A.S. Outbreaks of Siberian Silk Moth and Measures of Their Control; Nauka: Moscow, Russia, 1965; p. 179.

4. Kondakov, Y.P. Mass reproduction of Siberian silk moth. In Ekologiya Populyatsii Lesnykh Zhivotnykh Sibiri (Population Ecology of Forest Animals in Siberia); Nauka: Novosibirsk, Russia, 1974; pp. 206-264.

5. Florov, D.N. Pests of Siberian Forests; OGIX: Irkutsk, Russia, 1948; p. 143.

6. Foster, J.R.; Townsend, P.A.; Mladenoff, D.J. Spatial dynamics of a gypsy moth defoliation outbreak and dependence on habitat characteristics. Landsc. Ecol. 2013, 28, 1307-1320. [CrossRef]

7. Nifontov, S.V.; Savchenko, A.A.; Gridnev, A.N. Monitoring the development and forecasting of the mass reproduction (gradation) outbreaks of the Dendrolimus sibiricus Tschetv. in the Khabarovsk region. In IOP Conference Series: Earth and Environmental Science; IOP Publishing: Bristol, UK, 2019; Volume 316. [CrossRef]

8. Zhirin, V.M.; Knyazeva, S.V.; Eydlina, S.P. Long-term dynamics of vegetation indices in dark coniferous forest after Siberian moth disturbance. Contemp. Probl. Ecol. 2016, 9, 834-843. [CrossRef]

9. Kirichenko, N.I.; Baranchikov, Y.N.; Vidal, S. Performance of the potentially invasive Siberian moth Dendrolimus superans sibiricus on coniferous species in Europe. Agric. For. Entomol. 2009, 11, 247-254. [CrossRef] 
10. Kharuk, V.I.; Demidko, D.A.; Fedotova, E.V.; Dvinskaya, M.L.; Budnik, U.A. Spatial and temporal dynamics of Siberian silk moth large-scale outbreak in dark-needle coniferous tree stands in Altai. Contemp. Probl. Ecol. 2016, 9, 711-720. [CrossRef]

11. Flø, D.; Rafoss, T.; Wendell, M.; Sundheim, L. The Siberian moth (Dendrolimus sibiricus), a pest risk assessment for Norway. For. Ecosyst. 2020, 7, 48. [CrossRef]

12. Zhuravlev, P.G. Recommendations for Siberian Silkworm Control in the Forests of Russian Far East; FEFRI: Khabarovsk, Russia, 1960; p. 33.

13. Kharuk, V.I.; Im, S.T.; Soldatov, V.V. Siberian silkmoth outbreaks surpassed geoclimatic barrier in Siberian Mountains. J. Mt. Sci. 2020, 17, 1891-1900. [CrossRef]

14. Okunev, P.P. Geographical distribution and zones of injuriousness of Siberian silk moth. Geogr. Probl. For. 1955, 5, 13-24.

15. Kharuk, V.I.; Ranson, K.J.; Kuzmichev, V.V.; Im, S.T. Landsat-based analysis of insect outbreaks in southern Siberia. Can. J. Remote Sens. 2003, 29, 286-297. [CrossRef]

16. Kharuk, V.I.; Im, S.T.; Dvinskaya, M.L.; Golukov, A.S.; Ranson, K.J. Climate-induced mortality of spruce stands in Belarus. Environ. Res. Lett. 2015, 10, 125006. [CrossRef]

17. Thompson, L.M.; Faske, T.M.; Banahene, N.; Grim, D.; Agosta, S.J.; Parry, D.; Tobin, P.C.; Johnson, D.M.; Grayson, K.L. Variation in growth and developmental responses to supraoptimal temperatures near latitudinal range limits of gypsy moth Lymantria dispar (L.), an expanding invasive species. Physiol. Entomol. 2017, 42, 181-190. [CrossRef]

18. Isaev, A.S.; Ryapolov, B.Y. Analysis of the landscape-ecological confinement of the Siberian silkworm outbreaks using aerial survey. In Investigation of Taiga Landscapes Using Methods of Remote Sensing; Nauka: Novosibirsk, Russia, 1979; pp. 152-166.

19. Ryapolov, V.Y. Methods of creating maps of forest damage caused by insect pests. Geogr. Nat. Resour. 1985, 2, 97-106.

20. Egan, J.M.; Kaiden, J.; Lestina, J.; Stasey, A.; Jenne, J.L. Techniques to Enhance Assessment and Reporting of Pest. Damage Estimated with Aerial Detection Surveys; R1-19-09; U.S. Department of Agriculture, Forest Service, Northern Region, Forest Health Protection: Missoula, MT, USA, 2019; p. 33.

21. Meddens, A.J.H.; Hicke, J.A.; Vierling, L.A. Evaluating the potential of multispectral imagery to map multiple stages of tree mortality. Remote Sens. Environ. 2011, 115, 1632-1642. [CrossRef]

22. Lyamtsev, N.I. Forecasting Gypsy Moth Outbreaks, a Threat to Oak Forests and the Necessity of Preventing Measure; VNIILM: Pushkino, Russia, 2018; p. 84.

23. Townsend, P.A.; Singh, A.; Foster, J.R.; Rehberg, N.J.; Kingdon, C.C.; Eshleman, K.N.; Seagle, S.W. A general Landsat model to predict canopy defoliation in broadleaf deciduous forests. Remote Sens. Environ. 2012, 119, 255-265. [CrossRef]

24. Buotte, P.C.; Hicke, J.A.; Preisler, H.K.; Abatzoglou, J.T.; Raffa, K.F.; Logan, J.A. Climate influences on whitebark pine mortality from mountain pine beetle in the Greater Yellowstone Ecosystem. Ecol. Appl. 2016, 26, 2507-2524. [CrossRef]

25. Creeden, E.P.; Hicke, J.A.; Buotte, P.C. Climate, weather, and recent mountain pine beetle outbreaks in the western United States. For. Ecol. Manag. 2014, 312, 239-251. [CrossRef]

26. Polikarpov, N.P.; Chebakova, N.M.; Nazimova, D.I. Climate and Mountain Forests in Southern Siberia; Nauka: Novosibirsk, Russia, 1986; p. 225.

27. Smagin, V.N.; Ilinskaya, S.A.; Nazimova, D.I.; Novoseltseva, I.F.; Cherednikova, J.S. Forest Types of Mountains of Southern Siberia; Nauka: Novosibirsk, Russia, 1980; p. 336.

28. Bright, B.C.; Hicke, J.A.; Hudak, A.T. Estimating aboveground carbon stocks of a forest affected by mountain pine beetle in Idaho using lidar and multispectral imagery. Remote Sens. Environ. 2012, 124, 270-281. [CrossRef]

29. Bright, B.C.; Hudak, A.T.; Egan, J.M.; Jorgensen, C.L.; Rex, F.E.; Hicke, J.A.; Meddens, A.J.H. Using satellite imagery to evaluate bark beetle-caused tree mortality reported in aerial surveys in a mixed conifer forest in Northern Idaho, USA. Forests 2020, 11, 529. [CrossRef]

30. Wulder, M.A.; Dymond, C.C.; White, J.C.; Leckie, D.G.; Carroll, A.L. Surveying mountain pine beetle damage of forests: A review of remote sensing opportunities. For. Ecol. Manag. 2006, 221, 27-41. [CrossRef]

31. R Core Team. R: A Language and Environment for Statistical Computing; R Foundation for Statistical Computing: Vienna, Austria, 2020; Available online: https: / / www.R-project.org/ (accessed on 20 July 2020).

32. Liaw, A.; Wiener, M. Classification and regression by random forest. $R$ News 2002, 2, 18-22.

33. Chen, T.; He, T.; Benesty, M.; Khotilovich, V.; Tang, Y.; Cho, H.; Chen, K.; Mitchell, R.; Cano, I.; Zhou, T.; et al. Xgboost: Extreme Gradient Boosting. R Package Version 1.2.0.1. 2020. Available online: https:/ /CRAN.R-project.org/package=xgboost (accessed on 5 August 2020).

34. Kuhn, M. Caret: Classification and Regression Training. R Package Version 6.0-86. 2020. Available online: https://CRAN.Rproject.org / package=caret (accessed on 20 July 2020).

35. Hijmans, R.J. raster: Geographic Data Analysis and Modeling. R Package Version 3.3-13. 2020. Available online: https: / /CRAN.R-project.org / package=raster (accessed on 20 July 2020).

36. De la Giroday, H.-M.C.; Carroll, A.L.; Aukema, B.H. Breach of the northern Rocky Mountain geoclimatic barrier: Initiation of range expansion by the mountain pine beetle. J. Biogeogr. 2012, 39, 1112-1123. [CrossRef]

37. Haynes, K.J.; Allstadt, A.; Klimetzek, D. Forest defoliator outbreaks under climate change: Effects on the frequency and severity of outbreaks of five pine insect pests. Glob. Change Biol. 2014, 20, 2004-2018. [CrossRef] [PubMed] 
38. Eklundh, L.; Johansson, T.; Solberg, S. Mapping insect defoliation in Scots pine with MODIS time-series data. Remote Sens. Environ. 2009, 113, 1566-1573. [CrossRef]

39. MODIS/Terra + Aqua Land Cover Type Yearly L3 Global 0.05Deg CMG. NASA LP DAAC. Available online: https:/ /lpdaac. usgs.gov/products/mcd12c1v006/ (accessed on 20 July 2020).

40. Mezentsev, V.S.; Karnatsevich, I.V. Humidification of the West-Siberian Plain; Gidrometeoizdat: Saint Petersburg, Russia, $1969 ;$ p. 168. 